\title{
IN MEMORIAM PROF. E. VON HORNBOSTEL
}

DOOR

JHR. L. C. VAN PANHUYS

Op 28 November 1935 is te Cambridge in Engeland overleden Erich Maria von Hornbostel, de groote, geleerde muziekkenner, die o.a. dr. Herskovits heeft bijgestaan met de bewerking van door den laatsten in Suriname op wetenschappelijke wijze opgenomen liederen. Het is te hopen, dat het dr. Herskovits spoedig zal mogen gelukken om de uitkomsten van dat musicologisch onderzoek naar in het Zuid-Amerikaansche gebiedsdeel bij beschaafden en onbeschaafden verzamelde volksmelodieën openbaar te maken.

Prof. v. H. stamde van vaderszijde uit een oude (oorspronkelijk Hannoveraansche adellijke) familie; hij werd in 1877 te Weenen geboren en promoveerde er in 1900 tot Dr. phil. Te Berlijn stelde hij zich onder leiding van den hoogleeraar Stumpf; hij hield zich daar o.a. bezig met toonpsychologisch onderzoek en legde met prof. S. den grondslag voor een phonogrammenarchief, dat van 1906 af, toen hij juist was teruggekeerd van een muziekwetenschappelijke studiereis onder de Pawnee-Indianen, uitsluitend verder door hem werd verzorgd en dat, onder zijn leiding, uitgroeide tot de rijkste en beste verzameling van exotische muziek ter wereld. Van zijn Amerika betreffende verhandelingen worden hier vermeld: Phonographierte Indianer-Melodien aus Britsch Columbia (in Boas Anniversary Vol. 1906); Ueber einige Panpfeifen aus Nordwestbrasilien (in Th. Koch-Grünberg, Zwei Jahre unter den Indianern, 1910); Zwei Gesänge der Cora Indianer, I. Melodien und Formanalysen (in K. Th. Preuss, Die Nayarit-Expedition, 1912); Musik der Makuschi, Taulipàng und Yekuana (in Th. Koch-Grünberg, Vom Roroima zum Orinoco, Bd. III, 1923). Van zijn artikelen over Afrika noem ik African Negro-Music (in „Africa” I, 1928); van die over Indië Gesänge aus Seram (Molukken) (in O. D. Tauern, Patasiwa und Patalima, 1918). Het laatste met eenige voorliefde, omdat ik destijds daarvan een lied, tekst 
met notenschrift, heb overgenomen in een artikel (31 blz.) over wetenschappelijk onderzoek op Seran en over het boek van dr. Tauern, in het tijdschrift van het Kon. Ned. Aardrijkskundig Genootschap, weinig vermoedende dat ik vele jaren later nog eens met prof. von Hornbostel in briefwisseling zou komen.

Dr. (Mr.) Jaap Kunst, die mij door de welwillende toezending van een overdruk van zijn artikel „Bij den dood van Erich von Hornbostel", in het Januari-nummer 1936 van het Orgaan der Federatie van Nederlandsche Toonkunstenaars-vereenigingen, waarvan de secretaris, dr. K. Ph. Bernet Kempers te Amsterdam Harmoniehof $22^{1}$ gevestigd is, in staat heeft gesteld dit in memoriam te schrijven, wijst voorts op een aantal meer principieele en samenvattende artikelen, die de overledene deed verschijnen, zooals Musik der Naturvölker (in Meyer's Gr. Konversationslexicon, 1912); Vorschläge zur Transkription exotischer Melodien (in Sammelb. der I. M. G. XI, 1909); over Systematik der Musikinstrumente (in het Z. für Ethnol. 1914); over Musikalische Tonsysteme (in Geiger und Scheel, Handbuch der Physik, Bd. VIII, 1927) en nog vele andere. Tot zijn werk behooren tal van boekbesprekingen, welke in sommige gevallen uitgroeiden tot zelfstandige, boeiende verhandelingen met rijken inhoud, b.v. over American Negro-Songs (div. auteurs, in The Internat. Review of Missions, Vol. XV, No. 60, 1926). Men dankt hem ook de samenstelling van en een gedegen commentaar op door C. Lindström A. G. onder den titel „,Musik des Orients” uitgegeven verzameling gramofoonplaten van exotische muziek, welke het Westen eindelijk de oogen opende voor de bekoring en schoonheid, c.q. de merkwaardigheid, o.a. van Japansche, Chineesche, Balische, Javaansche, Soendaneesche, Voor-indische, Perzische en Tunesische muziek.

Een van de belangrijkste uitkomsten van zijn levenswerk was zijn ontdekking van het oud-Chineesche blaaskwintenstelsel en den invloed daarvan over een groot deel der Oude en Nieuwe Wereld. Hij heeft bijna met zekerheid aangetoond, dat eenzelfde metrische norm ten grondslag ligt aan de lengtemaatsystemen van Oud-China, Praecolumbiaansch Peru, de Sumerische en Babylonische rijken en Oud-Aegypte. In Die Herkunft der altperuanischen Gewichtsnorm (in „Anthropos” XXVI, 1931) toonde hij aan, dat ook deze norm zijn oorsprong vindt in Oost-Azië. Een reeks van verhandelingen getuigt van zijn psychophysiologische studiën. Hij maakte studie van oorsprong en beteekenis van het alphabet, en ook van de touw- (overneem-) spelletjes, die o.a. 
door prof. Pospičil (naar deze mij mededeelde) worden onderzocht en over welk onderwerp Dr. Lindblom zijn String figures in Africa (in Riksmuseets Etnografiska Avdelning Smärre Meddelanden, Nr 9, Stockholm, 1930) heeft geschreven. Ik merk even op, dat ik vermoed, dat deze spelen (cat-craddles, enz.) nog in Suriname o.a. bij de Boschnegers te vinden zullen zijn.

Tevens was hij een goed pianist en een meer dan verdienstelijk componist.

Deze zoo verbijsterend veelzijdig begaafde geest huisde in een zwak lichaam. Hij bezat een fijne humor en een kinderlijke blijmoedigheid. In 1917 is hij hoogleeraar geworden. Hij heeft (evenals verscheidene Duitsche en Oostenrijksche muzieketnologen) Nederlandsch geleerd, om kennis te kunnen nemen van hetgeen in die taal over Indonesische muziek is gepubliceerd. Nimmer stond het belang van zijn persoon op den voorgrond. Maar deze man, zegt Mr. Kunst, die niemand ooit heeft benadeeld, die de Duitsche wetenschap door zijn genialen arbeid nieuwen luister heeft bijgezet, werd, omdat zijn moeder en echtgenoote niet-, of niet geheel Arisch waren, het bestaan in het rijk onmogelijk gemaakt. In 1933 zag hij zich genoodzaakt Berlijn te verlaten en zijn geliefd Phonogramm-Archiv in den steek te laten. Wel werd hem te New-York een leerstoel aangeboden, doch de emoties over het onrecht hem en velen van zijn beste vrienden aangedaan, het drukkende gevoel met een zeer labiele gezondheid een nieuw leven te moeten opbouwen, gevoegd bij het ongewone klimaat en de enerveerende drukte van de grootste stad ter wereld, heeft zijn veerkracht gebroken en zijn hart aangetast.

Drie maanden zocht hij herstel op de Bermuda-eilanden. Van daar mocht ik van hem twee brieven ontvangen. Het verblijf bracht hem geen baat; hij moest zwaar ziek de Nieuwe Wereld verlaten en vond in Londen een onderkomen en medische verpleging.

Eere aan de Engelschen, die hem uitnoodigden naar Cambridge te komen, waar de Universiteit hem een stipendium toekende.

Ik heb de gedachte, dat de Surinaamsche volksgemeenschap geschikt is om ons eenmaal ook een muziekgenie te schenken. Een groot geleerde en een befaamd letterkundige hebben wij al van Suriname gekregen. Indien dan zulk een begaafd man moge voortkomen uit de Surinaamsche jeugd, moge hij dan ook tot hooger scheppen gebracht worden door zich in te denken wat von Hornbostel geleden heeft, en hoe hij niettemin tot het laatst toe zijn taak heeft willen vervullen. Een vorig geslacht heeft Mozart van den arme laten begraven. Zijn de menschen dan nog niet anders geworden? 
Mag ik van zijn beide brieven dit mededeelen. Over de verzameling Abbenhuis en Berkenveld schreef hij: Besten Dank für die Uebersendung des Manuskripts (van beide genoemde heeren) das ich Ihnen gleichzeitig eingeschrieben zurückschicke. Meine Befürchtung, dass Notierungen nach dem blossen Gehör für die Lieder unzureichend sein würden, ist gegenstandlos. Denn es handelt sich um rein europäische Volkslieder (u. Gassenhauer) ohne irgend eine Spur von Afrikanischen. Für die vergleichende Musikwissenschaft hat dieses Material daher keine Interesse. Verder: Etwa 200 Buschneger-Gesänge, die Dr. Herskovits in Surinam phonographisch aufgenommen hat, sind von Dr. Kolinsky transkribiert u. analysiert werden. Diese ausgezeichnete u. sehr sorgfältige Arbeit ist sowohl musikwissenschaftlich als etnologisch von ungewöhnlichem Interesse, da die Gesänge alle Abstufungen von reinsten afrikanischen Schwarz bis zum reinen europäischen Weiss zeigen... Prof. H. heeft zich dus, hoewel krank, de moeite getroost het groote aantal liederen nauwkeurig te onderzoeken. Zijn laatste brief, blijkbaar door hem gedicteerd, want de onderteekening ontbreekt, hoop ik, indien de Redactie van dit tijdschrift het mij wil toestaan, dat hieronder als een teeken mijnerzijds van eerbied voor zijn nagedachtenis moge worden gedrukt.

Creekside, Pembroke, Bermuda, den 4.5.1934.

Jonkheer L. C. van Panhuys

Burgomaster

Councilhouse

Vuren (G.).

Netherlands.

Sehr geehrter Herr van Panhuys,

Haben Sie besten Dank für Ihren Brief vom 2 ten April und die beigelegten Ergänzungen zu dem Artikel über Surinam-Volkslieder. Mein Urteil über diese Arbeit hat sich durch die Anmerkungen nicht geändert. Den Abdruck der langen Zitate aus dem sehr oberflächlichen und gänzlich unwissenschaftlichen Buch von Albert Friedenthal kann ich keineswegs empfehlen.

Für Ihre freundliche Empfehlung der Zeitschrift „,De West-Indische Gids" bin ich Ihnen zu besonderem Dank verpflichtet. Es ist inzwischen eine neue Hoffnung aufgetaucht, die Kolinskische Arbeit in Amerika zum Druck bringen zu können, und ich will erst das Ergebnis unserer Bemühungen in dieser Hinsicht abwarten ehe ich mich nach Holland wende.

\author{
Mit besten Empfehlungen \\ in ausgezeichneter Hochachtung \\ Ihr sehr ergebener
}

